\title{
Parasites of Cultured Tiger Puffer (Takifugu rubripes) and their Seasonal Occurrences, with Descriptions of Two New Species of Gyrodactylus
}

\author{
Kazuo Ogawa*1 and Kiyoshi Inouye*2 \\ *1Department of Aquatic Bioscience, Faculty of Agriculture, The University of Tokyo, Bunkyo-ku, Tokyo 113, Japan \\ ${ }^{*} 2$ National Research Institute of Aquaculture, Tamaki-cho, Watarai-gun, Mie 519-04, Japan
}

(Received July 16, 1996)

\begin{abstract}
Parasites of cultured tiger puffer, Takifugu rubripes, produced in a hatchery, introduced to a culture site in Nagasaki Prefecture in summer and cultured for one year and a half in net cages, were examined bimonthly.

Thirteen species of parasites were recorded: ciliates, Trichodina fugu and T. jadranica on the gills, Cryptocaryon irritans in the fins and body surface; myxosporeans, Kudoa shiomitsui in the heart and Multivalvulida gen. sp. (syn.: Septemcapsula yasunagai Hsieh et Chen, 1984) in the brain; monogeneans, Gyrodactylus rubripedis $\mathrm{sp} . \mathrm{n}$. on the fins and body surface and Heterobothrium okamotoi on the gills and branchial cavity wall; trematodes, Tetrochetus sp. and Maculifer pacificus in the rectum; acanthocephalan, Longicollum pagrosomi in the rectum; copepods, Caligus fugu on the buccal cavity wall, Pseudocaligus fugu on the body surface and Neobrachiella hugu (syn: Clavellopsis hugu Yamaguti, 1939) on the buccal cavity wall.

Gyrodactylus rubripedis sp. $\mathrm{n}$. is different from the most closely related G. pardalidis $\mathrm{sp}$. n. collected from the fins of panther puffer, Takifugu pardalis and finespotted puffer, T. poecilonotus in smaller size of hamuli and shape of the marginal hook proper; the two new gyrodactylids are similar to ones from freshwater fish of the genus Noemacheilus in having inwardly bent root of hamuli, but clearly separated from them by the shape of the ventral bar.

In some selected species of parasites, seasonal occurrences are described and possible sources of infection are discussed.
\end{abstract}

Key words: Takifugu rubripes, tiger puffer, parasite fauna, new species, Monogenea

Culture of tiger puffer, Takifugu rubripes, started in western Japan in the 1950s (Okamoto, 1963), the annual production staying less than 100 metric tons during the 1950s-1970s. In those early years, feral puffers were caught in spring and summer, and cultured until winter, when most of puffers were consumed. Since the 1980s, however, the puffer culture industry has been rapidly growing. The annual culture production of tiger puffer exceeded 4,000 metric tons in 1992, about 10 times as much as that of 10 years before. This is mainly because of a plentiful supply of artificially produced juveniles, which has led to the recent expansion of tiger puffer culture. With the change of the source of seedlings, culture methods have substantially changed. Typically, hatchery-produced juveniles are available to fish farmers in summer, and cultured for about 1 year and a half until marketed in winter.

With regard to diseases associated with puffer culture, much remains to be studied, because of a rather short culture history. A total of 18 species of parasites have so far been reported from tiger puffer, but information about their pathogenicity is quite limited. As for ciliate parasites, Cryptocaryon irritans was first reported from tiger puffer as an unidentified ciliate by Sikama (1937) and two species of Trichodina viz. T. fugu and $T$. jadranica were described by Imai et al. (1997). As for myxosporeans, Kudoa shiomitsui was described by Egusa and Shiomitsu (1983) and Multivalvulida gen. sp. by Egusa (1986). The latter myxosporean was named as Septemcapsula yasunagai as a new genus and a new species by Hsieh and Chen (1984), but there is some discussion about its validity of the new species (Egusa, 1986), and thus it is treated here as an unidentified myxosporean as above. There are 13 species of metazoan parasites, of which are 3 species of monogeneans: Udonella caligorum reported by Yamaguti (1958), Neobenedenia girellae by Ogawa et al. (1995) and Heterobothrium okamotoi first reported by Okamoto (1963) as H. tetrodonis and later described by Ogawa (1991) as a new species, 3 species of trematodes: 
Galactosomum sp. metacercaria by Yasunaga et al. (1981), Pharyngora orientalis by Yamaguti (1934) and Psettarium japonicum by Yamaguti (1938), 3 species of namatodes: Anisakis sp. larva by Yamaguti (1941), Contracaecum sp. larva by Fukuda et al. (1982) and Cuculanidae gen. sp. (originally ?Spirruroidea cuculanidae?) by Okamoto and Ogasawara (1965), and 4 species of copepods: Taeniacanthus yamagutii first reported by Okamoto and Ogasawara (1965) as Irodes yamagutii, Caligus fugu described by Yamaguti and Yamasu (1959a), Neobrachiella hugu, originally described by Yamaguti (1939) as Clavellopsis hugu, Argulus scutiformis by Yamaguti and Yamasu (1959b).

In this paper, an attempt is made to identify parasites which appeared during a survey throughout the whole period of culture and to describe their patterns of occurrences, thus to provide basic information on parasite infections of cultured tiger puffer.

\section{Materials and Methods}

Hatchery-reared juveniles of tiger puffer cultured at a farm at Naru, Minami-Matsuura gun, Nagasaki Prefecture, Japan were used in this study. They were cultured in an off-shore net pen and fed daily with defrozen minced fish. Following the introduction of the puffer seedlings to the farm early in July 1986, 20 individuals were randomly collected bimonthly from a single fish stock and examined for parasites from July 1986, when they were $9.0 \pm 0.8 \mathrm{~cm}$ in body length, 25.0 $\pm 7.4 \mathrm{~g}$ in body weight, until November 1987 , soon before harvested ( $28.8 \pm 1.2 \mathrm{~cm}$ long, $838 \pm 145 \mathrm{~g}$ in weight) (Fig. 1). Water temperature ranged from 13.5 to $28.0^{\circ} \mathrm{C}$ during the survey period. Preliminary parasitological surverys of juvinile puffers were made on May 16, 1986, when the fish had still been reared in a hatchery in Nagasaki Pref., and on July 4, a few days after arrival of
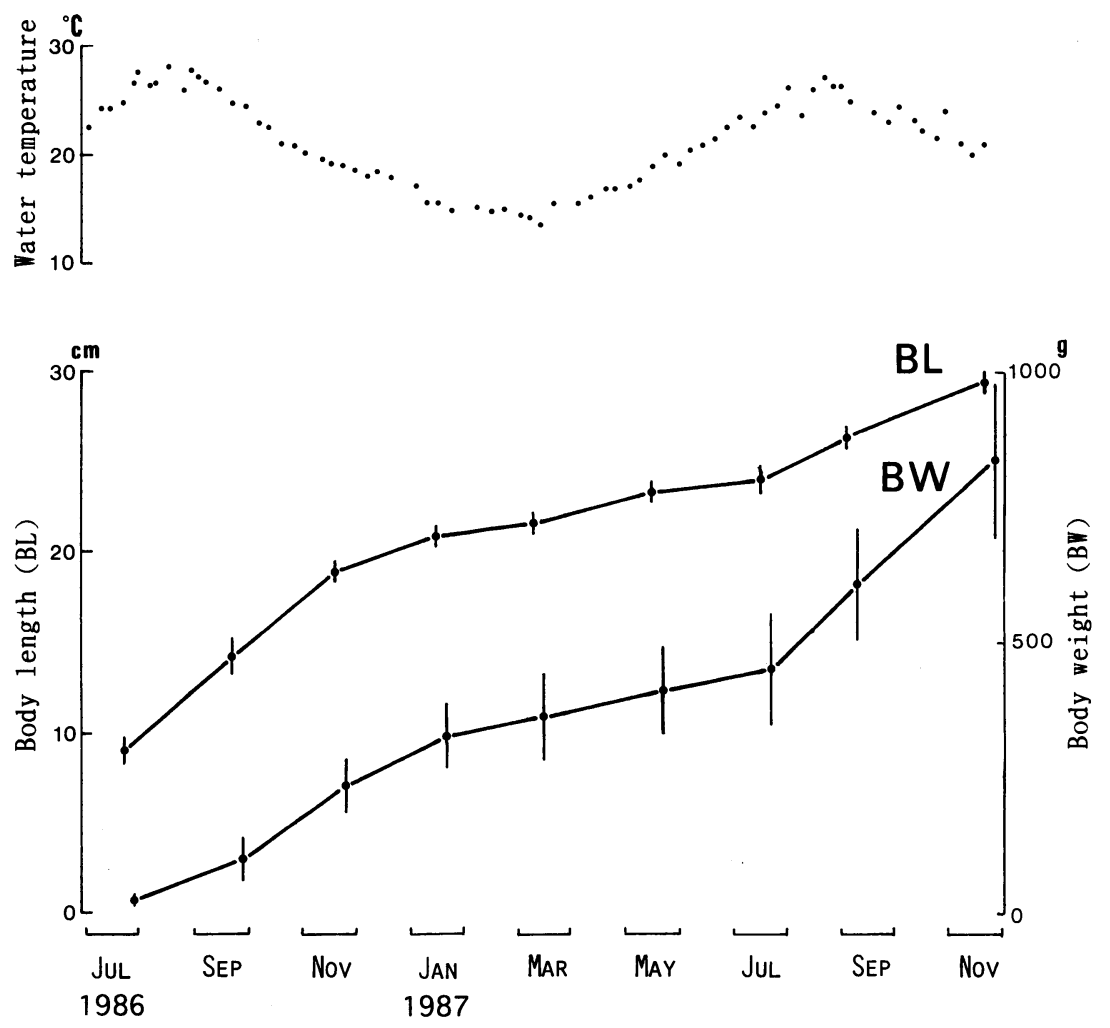

Fig. 1. Fluctuation of water temperature and growth of tiger puffer during the study period (July 1986-Nov 1987) at Naru, Nagasaki Prefecture. 
the seedlings at the farm, 25 days before the first rugular sampling.

Parasitological surveys were carried out for ectoparasites on the gills, fins (pelvic, dorsal and anal) and body surface scrapings under a stereo-microscope, and the branchial and buccal cavity wall by the naked eye, and for endoparasites in the intestine, heart, brain under a stereo-microscope. Specifically, gill trichodinids were fixed in $5 \%$ formalin solution, and observed in wet mount under a compact microscope for identification. For practical reasons, trichodinids on the fins and body surface were not collected. Myxosporean spores in the brain, heart and gills were smeared on a slide glass and stained with May-Grunwald and Giemsa. Gyrodactylids on the fins and body surface were fixed in ammonium picrate-glycerin solution, and permanent mount preparations were made according to the method of Ergens (1969). Other helminths were fixed in AFA, stained with alum carmine or Heidenhein's iron hematoxylin, dehydrated in alcohol series and mounted in Canada balsam. Parasitic copepods were fixed in $70 \%$ alcohol and observed in lactic acid.

Gyrodactylus from tiger puffer were compared with those from other puffer species of the genus Takifugu, namely $T$. pardalis at Hagi, Yamaguchi Prefecture in April 1987 and T. peocilonotus at Nomo, Nagasaki Pref. in June 1986. Drawings of Gyrodactylus species were made with the aid of a camera lucida. Measurements are given in $\mu \mathrm{m}$, unless otherwise stated.

\section{Results}

\section{Description of parasites}

Gydodactylus rubripedis sp. $\mathrm{n}$.

(Fig. 2)

Habitats: fins and body surface of tiger puffer, Takifugu rubripes (Temminck et Schlegel).

Type locality and date: Naru, Nagasaki Prefecture, Japan (32 $\left.52^{\prime} \mathrm{N}, 128^{\circ} 56^{\prime} \mathrm{E}\right)$; May 21, 1987.

Additional record: Naru, Nagasaki Prefecture, Nov. 27, 1986, Mar. 16, 1987, July 23, 1987.

Specimens deposited: Meguro Parasitological Museum, Tokyo, M. P. M. Coll. No. 19696.

Description (based on 14 specimens): Body 0.39$0.56 \mathrm{~mm}$ long. Hamuli 47-53 long excluding folded part of root; base 40-46 long, point 27-29 long, root folded inwardly in middle. Ventral bar 20-25 long by 5-6 wide; well-developed ear-shaped processes, 9-15 long; membrane 11-15 long, with rounded margin. Dorsal bar 16-25 long by $1.5-2$ wide, slightly swallen in middle. Marginal hooks 19-21 in total length; handle 15-17 long; domus 8-10 long; hook proper 4 in length by $3.5-4$ in distal width and 3-3.5 in proximal width. Male copulatory organ 11-16 in diameter; cirrus 3.55.5 long guarded by a single row of 4-7 minute spines.

Remarks: This parasite is unique in having inwardly bent root of hamuli. Similar structure was reported in Gyrodactylus species parasitic on Noemacheilus and its closely related genera of freshwater fish hosts (Ergens and Kartunova, 1991). The present new species, together with the following $G$. pardalidis sp. n., seems to form an independent species group within the genus Gyrodactylus.

\section{Gydodactylus pardalidis sp. $\mathrm{n}$.}

(Figs. 3 and 4)

Habitat: fins of panther puffer, Takifugu pardalis (Temminck et Schlegel).

Type locality and date: Hagi, Yamaguchi Prefecture, Japan (34 $\left.25^{\prime} \mathrm{N}, 131^{\circ} 23^{\prime} \mathrm{E}\right)$; Apr. 23, 1987.

Additional record: fins of finespotted puffer, Takifugu poecilonotus (Temminck et Schlegel); Nomo, Nagasaki Prefecture; June 17, 1986.

Specimens deposited: Meguro, Pasasitological Museum, Tokyo, M. P. M. Coll. No. 19697-19698.

Description (based on 11 specimens): Body 0.33$0.67 \mathrm{~mm}$ long. Hamuli 35-43 long excluding folded part of root; base 28-35 long, point 19-24 long, root folded inwardly in middle. Ventral bar 17-24 long by 3.5-5.5 wide; ear-shaped processes 6.5-8.5 long; membrane 9-12 long, with rounded margin. Dorsal bar 15-22 long by 1-2 wide, slightly swallen in middle. Marginal hooks 18-21 in total length; handle 14-17 long; domus 8.5-10 long; hook proper 4-4.5 in length by 3.54.5 in distal width and 3-3.5 in proximal width. Male copulatory organ 9-14 in diameter; cirrus 3-5.5 long guarded by a single row of 4-6 minute spines.

Remarks: $\quad G$. pardalidis sp. n. is most similar to $G$. rubripedis sp. n., but different in smaller size of hamuli and shape of the marginal hook proper.

\section{Occurrences of parasites}

In the two preliminary monitorings, no parasites were found from fish in the hatchery in May (no. of fish examined=16), but 3 fish were already infected with Longicollum pagrosomi in the rectum among 12 fish examined in July, a few days after the arrival at the farm.

A total of 13 species of parasites were found in or on tiger puffer during the regular survey period from July 29, 1986 to Nov. 26, 1987 (Table 1). Among them, 

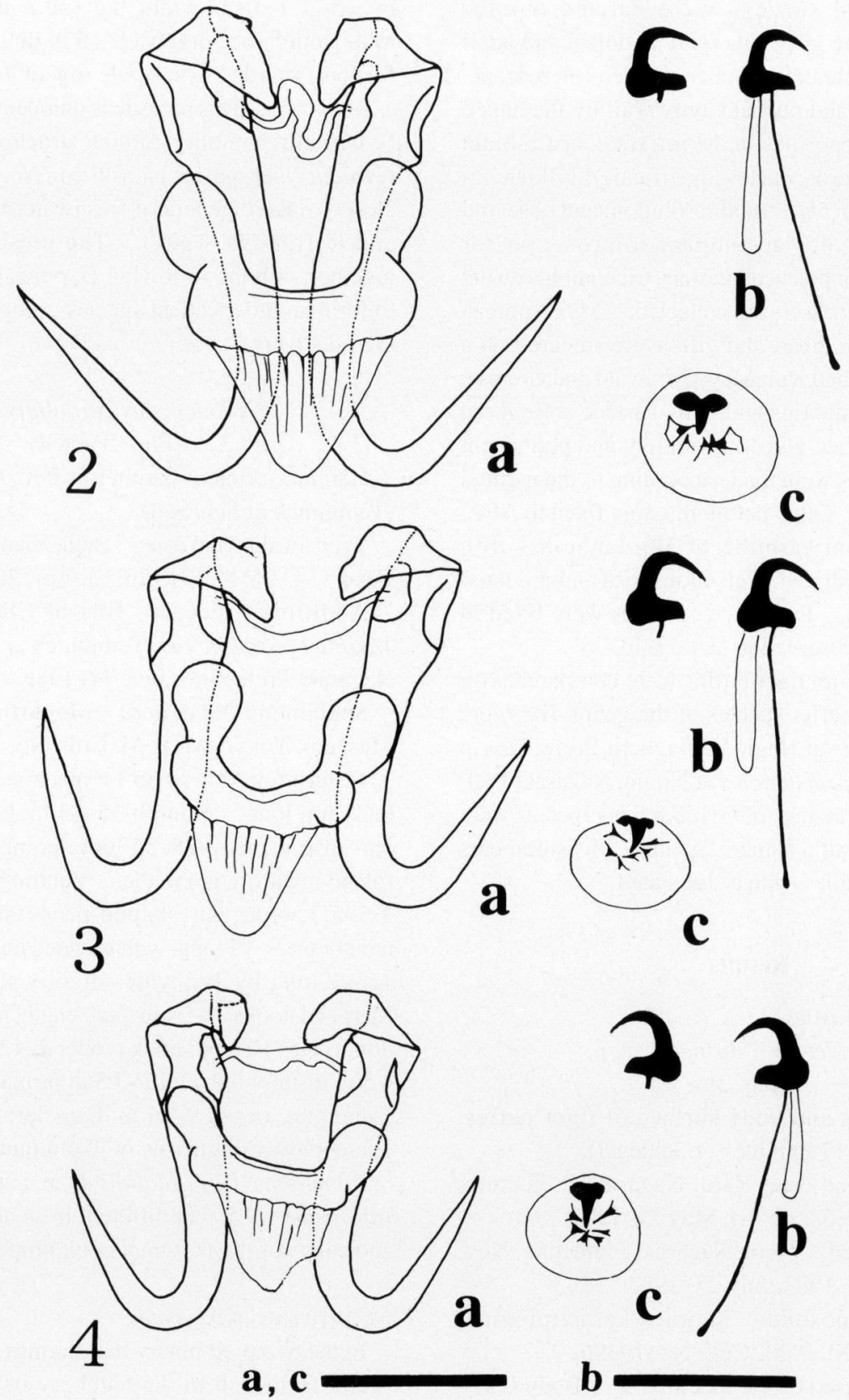

Figs. 2-4. Hard parts of Gyrodactylus species from the fins and body surface of puffers of the genus Takifugu. 2, Gyrodactylus rubripedis sp. n. from tiger puffer, Takifugu rubripes; 3, Gyrodactylus pardalidis sp. n. from Takifugu pardalis; 4, Gyrodactylus pardalidis sp. n. from Takifugu poecilonotus. a, hamuli and bars; b, marginal hooks; c, male copulatory organ. Left scale for a and c, $20 \mu \mathrm{m}$; right scale for b, $10 \mu \mathrm{m}$. 
Table 1. List of parasites recovered from cultured tiger puffer Takifugu rubripes in this study

\begin{tabular}{l}
\hline \hline Ciliata \\
Trichodina fugu Imai, Inouye, Kotani et Ogawa, 1997 \\
(gills) \\
Trichodina jadranica (Raabe, 1958) (gills) \\
Cryptocaryon irritans Brown, 1951 (fins, body surface) \\
Myxozoa \\
Kudoa shiomitsui Egusa et Shiomitsu, 1983 (heart) \\
Multivalvulida gen. sp. (brain) \\
$\quad$ syn. Septemcapsula yasunagai Hsieh et Chen, 1984 \\
Monogenea \\
Gyrodactylus rubripedis sp. n. (fins, body surface) \\
Heterobothrium okamotoi Ogawa, 1991 \\
(gills, branchial cavity wall) \\
Trematoda \\
Tetrochetus sp. (rectum) \\
Maculifer pacificus Yamaguti, 1938 (rectum) \\
Acanthocephala \\
Longicollum pagrosomi Yamaguti, 1935 (rectum) \\
Copepoda \\
Caligus fugu Yamaguti et Yamasu, 1959 \\
(buccal cavity wall) \\
Pseudocaligus fugu Yamaguti, 1936 (body surface) \\
Neobrachiella hugu (Yamaguti, 1939) \\
(buccal cavity wall) \\
syn: Clavellopsis hugu Yamaguti, 1939
\end{tabular}

Cryptocaryon irritans, Multivalvulida gen. sp., Tetrochetus sp., Maculifer pacificus, Caligus fugu and Pseudocaligus fugu were only occasionally found, and seasonality on the occurrence was not clearly demonstrated. Thus, infections of the remaining 7 species of parasite were examined in detail (Fig. 5).

\section{Trichodina fugu and Trichodina jadranica}

As is shown in Fig. 5, all the fish examined were infected with Trichodina spp. throughout the study period. Identification of the two trichodinids revealed that Trichodina fugu was always a dominant species on the gills (data not shown).

\section{Kudoa shiomitsui}

The myxosporean was found all the time, with varying prevalences of infection. Seasonality of infection was not clear.
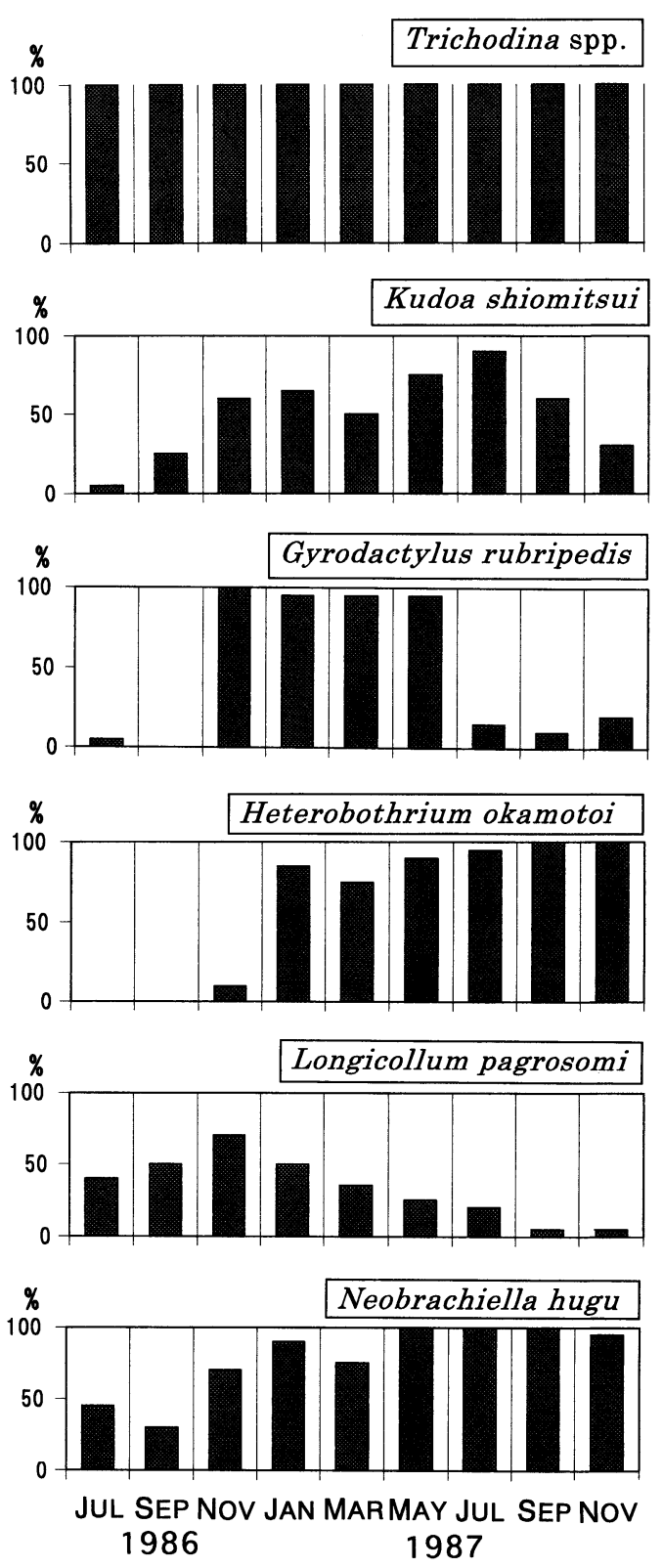

Fig. 5. Seasonal changes in prevalences of infection of tiger puffer with some parasites during the survey period.

\section{Gyrodactylus rubripedis sp. $\mathrm{n}$.}

Although not all parts of fins and body surface were examined, the monogenean was sometimes found in large numbers, the highest number per fish being 50 . The parasite tended to be abundant in winter. 

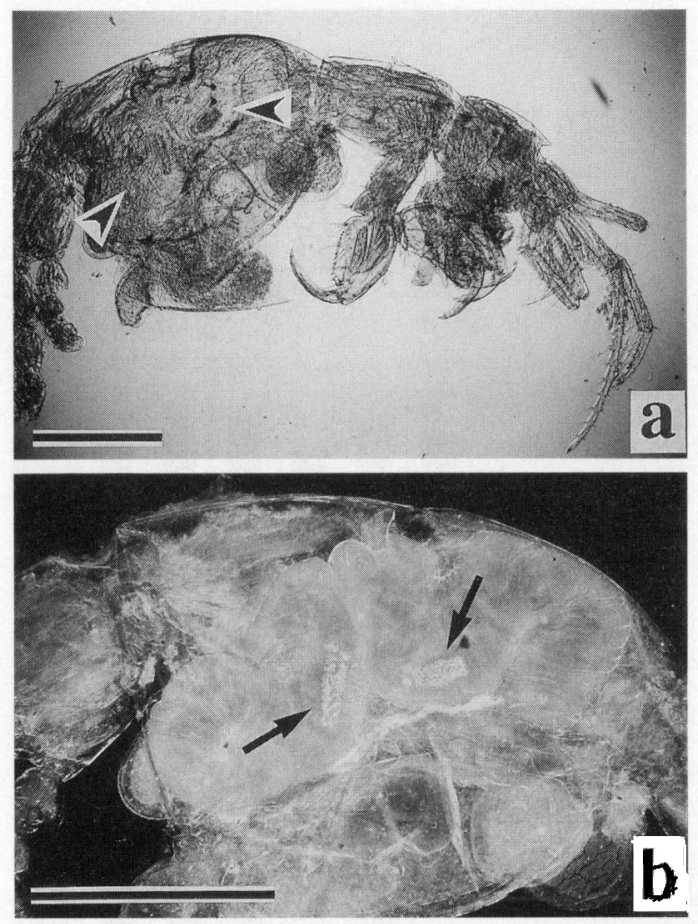

Fig. 6. Amphipod, Caprella acutifrons, found in the intestine of tiger puffer. a, major part of body of the amphipod with two cystacanth larvae (arrowheads) of Longicollum pagrosomi in the body cavity; b, enlargement of a, taken under dark-field illumination. Probosci are indicated by arrows. Scale, $1 \mathrm{~mm}$.

\section{Heterobothrium okamotoi}

This monogenean was first recovered on the gills in Nov. 1986, about 5 months after introduction of the puffers to the farm, and found also on the branchial cavity wall in Jan, 1987. The prevalence of infection stayed high $(75-100 \%)$ until the end of the survey. Parasites on the gills were always immature, while those on the branchial cavity wall were mostly adult. There was no correlation between the number of parasites on the two habitats of the host (data not shown). The highest number of parasites per fish was 56 .

\section{Longicollum pagrosomi}

In one of the three fish infected with the acanthocephalan in the preliminary survey in July 1986, the amphipod, Caprella acutifrons, containing two cystacanth stage larvae of $L$. pagrosomi in the body cavity, was found in the intestine (Fig. 6a, b). It was demonstrated that the amphipod acts as an intermediate

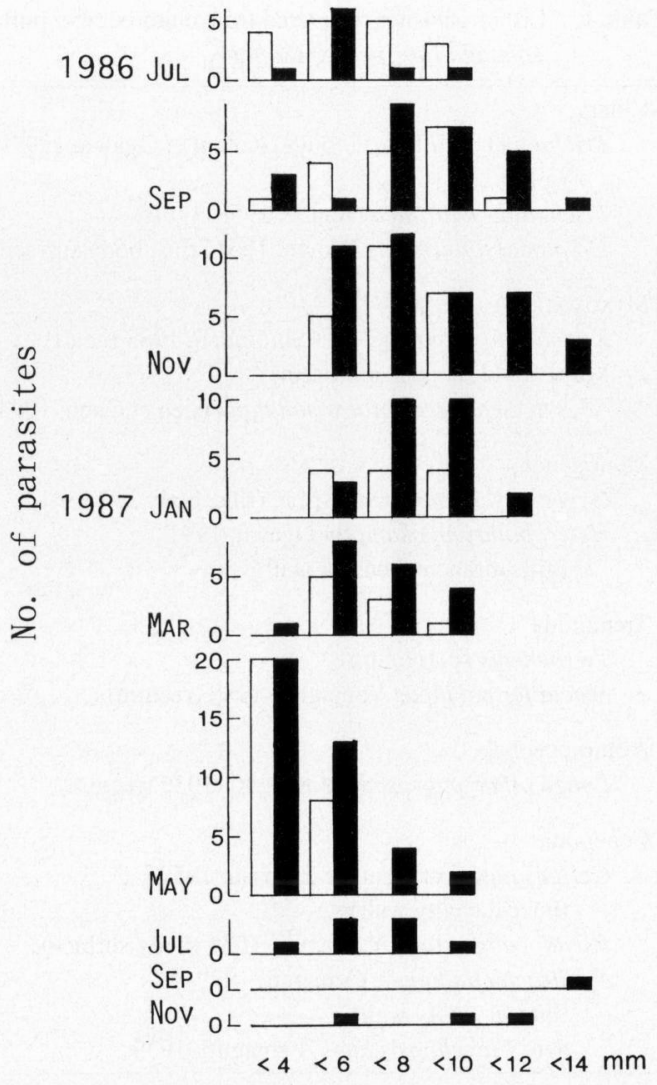

Fig. 7. Seasonal changes in frequency distribution of body length of Longicollum pagrosomi from the rectum of tiger puffer. White and black bars represent male and female specimens, respectively.

host for the acathocephalan.

Seasonal succession of the frequency distribution of parasite body length (Fig. 7) suggests that the parasite has a one-year life cycle and that invades the fish in summer. Largest worm measured $12.8 \mathrm{~mm}$ long, and only a few fully formed eggs were observed in the female body cavity.

\section{Neobrachiella hugu}

This species was a very common parasite, and found throughout the survey period. The mean intensity of infection stayed low (0.4-2.8) in the first year, but it rose to 5.6-6.7 from July to November in the second year. No clear seasonal change was noticed in the prevalence of adults with egg sacs or of immature forms. These results suggest that copepodids, the infective stage 
of the parasite, infect the fish all the year round with a peak period in warm water months.

\section{Discussion}

Thirteen species of parasites were recorded from tiger puffer in this study. Among them, 5 species, including one new species, were first reported from tiger puffer; Gyrodactylus rubripedis sp. n., Tetrochetus sp., Macurifer pacificus, Longicollum pagrosomi and Pseudocaligus fugu.

Since no parasite was found from juvenile puffers reared in the hatchery, it was thought that tiger puffer had mostly been infected with the parasites after arriving at the farm. However, Kudoa shiomitsui may have invaded the fish in the hatchery, for the myxosporean was already recovered from fish only about one month after the arrival. One-year old tiger puffer and several other fish species, i. e. yellowtail, Seriola quinqueradiata, and red sea bream, Pagrus major, had also been cultured in the same area, when juvenile puffers were introduced there. It is likely that the older puffers and other species of fish contributed as the source of infection of the young puffers with a possible exception for $K$. shiomitsui.

Okamoto (1963) described the life cycle of Heterobothrium tetrodonis $(=H$. okamotoi). A very unusual observation in his description was that the oncomiracidium, after settling down on the gills or branchial cavity wall of tiger puffer and shedding the cillia, encysted for a while in the host tissue. We sometimes observed encapsulation of this parasite on the branchial cavity wall. This was a host reponse to the parasite, and most probably he erroneously thought that the encapsulation was part of a developmental stage of the parasite.

In the present study, adult parasites of $H$. okamotoi were found only on the branchial cavity wall, while parasite on the gills were immature. This difference in the habitat of adult and immature parasites on the host strongly suggests that the monogenean migrates from the gills to the branchial cavity wall in the life cycle. The observation in this study will be described in more detail separately (Ogawa and Inouye, 1997a; 1997b).

Acanthocephalan infections of vertebrates are closely related to the feeding habits of the hosts. It was demonstrated that puffers not only were fed minced fish but also spontaneously ingested small invertebrates like amphipods propagated on the net meshing, and that the amphipod, Caprella acutifrons, is an intermediate host for Longicollum pagrosomi. Yasumono and Nagasawa
(1996) experimentally demonstrated that amphipods Carpella equilibra, C. californica and Jassa sp. aff. marmorata act as the intermediate hosts for $L$. pagrosomi, though they did not specify any of the three amphipods harbored the infective stage of the parasite. The acanthocephalan has been reported from many species of marine fishes, but mature worms were recovered only from red sea bream, Pagrosomus unicolor (=Pagrus major) (Yamaguti, 1935). This is the first record of the acanthocephalan from tiger puffer, but it seems that tiger puffer is not a suitable host for the acanthocephalan; specimens collected from puffers were considerably smaller than those from red sea bream (Yamaguti, 1935), and poorly matured.

Cryptocaryon irritans, Gyrodactylus rubripedis sp. n., Heterobothrium okamotoi and Pseudocaligus fugu sometime heavily infect cultured tiger puffer, and are considered pathogens. In the present survey, however, they appeared only occasionally, except for $H$. okamotoi. Trichodina spp. were ubiquitous parasites in this study. Although no quantitative study of the infection was conducted, fish infected with Trichodina did not show any sign of disease. Longicollum pagrosomi and Neobrachiella hugu provoked local hyperplasia of host tissue at the attachment site in the rectum and on the buccal cavity wall, respectively, but the intensity of infection with the two parasites never reached a state to cause disease. On the other hand, H. okamotoi occurred almost on all tiger puffer examined in the second year. The pathogenicity of $H$. okamoto $i$ will be described separately (Ogawa and Inouye, 1997b).

\section{Acknowledgements}

We would like to thank Dr. R. Ergens, Institute of Parasitology, Czech Academy of Sciences, Ceske Budejovice, Czech Republic for help in description of Gyrodactylus species, and Dr. Z. Kabata, Pacific Biological Station, Nanaimo, B. C., Canada for identification of parasitic copepods, Dr. T. Shimazu, Nagano-ken Junior College, Nagano, Japan for identification of the trematode Tetrochetus sp., Dr. I. Takeuchi, Otsuchi Marine Research Center, Ocean Research Institute, the University of Tokyo, Otsuchi, Iwate, Japan for identification of the amphipod in the intestine of tiger puffer. Appreciation is also extended to Mr. T. Kakimori, Naru, Nagasaki Pref., for providing fish samples, and to the late Mr. S. Inouye, Daiichi Pharmaceutical Co., Ltd., Tokyo, for his help in the field. 


\section{References}

Egusa, S. (1986): A myxosporean of the order Multivalvulida from the brain of Lateolabrax japonicus and some other marine fishes. Fish Pathol., 21, 233-238.

Egusa, S. and T. Shiomitsu (1983): Two new species of the genus Kudoa (Myxosporea: Multivalvulida) from marine cultured fishes in Japan. Fish Pathol., 18, 163-171. (In Japanese, with English summary.)

Ergens, R. (1969): The suitability of ammonium picrate glycerin in preparing slides of lower Monogenoidea. Folia Parasitol., 16, 320.

Ergens, R. and E. V. Kartunova (1991): Gyrodactylus gvozdevi n. sp. (Gyrodactylidae: Monogenea) from Noemacheilus dorsalis (Kessler) in Kazakhstan. Syst. Parasitol., 18, 117120.

Fukuda, T., Y. Tongu, T. Aji, J.-S. Lai, H.-L. Shing, K. Sumino and S. Inatomi (1982): Anisakidae larvae from some fishes in the Seto Inland Sea. Jpn. J. Parasitol., 31, 171-176. (In Japanese, with English summary.)

Hsieh, S.-R. and C.-L. Chen (1984): Septemcapsula yasunagai gen. et sp. nov., representative of a new family of the class Myxosporea. Acta Zootax. Sin., 9, 225-227. (In Chinese, with English summary.)

Imai, S, K. Inouye, T. Kotani and K. Ogawa (1997): Two trichodinid species from the gills of cultured tiger puffer, Takifugu rubripes, in Japan, with the description of a new species. Fish Pathol. 32, 1-6.

Ogawa, K. (1991): Redescription of Heterobothrium tetrodonis (Goto, 1894) (Monogenea: Diclidophoridae) and other related new species from puffers of the genus Takifugu (Teleostei: Tetraodontidae). Jpn. J. Parasitol., 40, 388-396.

Ogawa, K. and K. Inouye (1997a): Heterobothrium infection of cultured tiger puffer, Takifugu rubripes - A field observation. Fish Pathol., 32, 15-20.

Ogawa, K. and K. Inouye (1997b): Heterobothrium infection of cultured tiger puffer, Takifugu rubripes - Infection experiments. Fish Pathol., 32, 21-27.

Ogawa, K., M. G. Bondad-Reantaso, M. Fukudome and H. Wakabayashi (1995): Neobenedenia girellae (Hargis, 1955)
Yamaguti, 1963 (Monogenea: Capsalidae) from cultured marine fishes of Japan. J. Parasitol., 81, 223-227.

Okamoto, T. (1963): On the problems of a monogenetic trematode infection of puffers from Inland Sea of Japan. Suisanzoshoku (Special Issue), 3, 17-29. (In Japanese.)

Okamoto, T. and Y. Ogasawara (1965): Parasite occurrences of tiger puffer in natural waters. Ann. Rep. Naikai Reg. Fish. Lab., Ser. A, 2, 42-43. (In Japanese.)

Sikama, Y. (1937): On marine white spot disease. Suisangakkaiho, 7, 149-160. (In Japanese.)

Yamaguti, S. (1934): Studies on the helminth fauna of Japan. Part 2. Trematodes of fishes, I. Japan. J. Zool., 5, 249 541.

Yamaguti, S. (1935): Studies on the helminth fauna of Japan. Part 8. Acanthocephala, I. Japan. J. Zool., 6, 247-278.

Yamaguti, S. (1938): Studies on the helminth fauna of Japan. Part 21. Trematodes of fishes, IV. Publ. by author, 1-139.

Yamaguti, S. (1939): Parasitic copepods from fishes of Japan. Part 6. Lernaeopodoida, I. Vol. Jub. Prof. Yoshida, 2, 529578.

Yamaguti, S. (1941): Studies on the helminth fauna of Japan. Part 33. Nematodes of fishes, II. Japan. J. Zool., 9, 343 396.

Yamaguti, S. (1958): Studies on the halminth fauna of Japan. Part 52. Trematodes of fishes, XII. Publ. Seto Mar. Biol. Lab., 7, 53-88.

Yamaguti, S. and T. Yamasu (1959a): Parasitic copepods from fishes of Japan, with descriptions of 26 new species and remarks on two known species. Biol. J. Okayama Univ., 5, 89-165.

Yamaguti, S. and T. Yamasu (1959b): On two species of Argulus (Branchiura, Crustacea) from Japanese fishes. Biol. $J$. Okayama Univ., 5, 167-175.

Yasumoto, S. and K. Nagasawa (1996): Possible life cycle of Longicollum pagrosomi (Acanthocephala: Pomphorhynchidae) at fish farms. Fish Pathol., 31, 235-236.

Yasunaga, N., S. Ogawa, E. Hirakawa, K. Hatai, S. Yasumoto and H. Yamamoto (1981): On the marine-fish disease caused by Galactosomum sp. with special reference to its species and life cycle. Bull. Nagasaki Pref. Inst. Fish., 7, 65-76. (In Japanese.) 